\title{
Structural determination of ananatoside A: an unprecedented 15- membered macrodilactone-containing glycolipid from Pantoea ananatis
}

Charles Gauthier ${ }^{\mathrm{a}, \dagger}, *$, Serge Lavoie ${ }^{\mathrm{b}, \dagger}$, Marianne Piochon $^{\mathrm{a}}$, Sarah Martinez ${ }^{\mathrm{a}}$, Sylvain Milot ${ }^{\mathrm{a}}$, Eric Déziel ${ }^{\mathrm{a}, *}$

${ }^{a} I N R S$ - Institut Armand-Frappier, Université du Québec, 531, boul. des Prairies, Laval (Québec), Canada, H7V $1 B 7$

${ }^{b}$ Institut des Sciences de la Forêt Tempérée, Université du Québec en Outaouais, 58, rue Principale, Ripon (Québec), Canada, J0V 1 VO

${ }^{\dagger}$ These authors contributed equally to this work.

*Corresponding authors. Tel.: +1 450-687-5010; E-mail addresses:

charles.gauthier@iaf.inrs.ca (C. Gauthier); eric.deziel@iaf.inrs.ca (E. Déziel).

\begin{abstract}
The bacterium Pantoea ananatis was reported to produce glycolipid biosurfactants of unknown structures. Herein, we present the isolation and structural determination of ananatoside A, the main congener of a new family of 15-membered macrodilactone-containing glucolipids. The structure of ananatoside A was elucidated via chemical degradation and spectroscopic methods including 1D/2D NMR analysis, tandem MS/MS, GC-MS, HR-ESI-TOF-MS, MALDI-TOFMS, and polarimetry. Computational methods were used to predict the most abundant conformers of ananatoside A.
\end{abstract}

Keywords: Pantoea ananatis, glycolipid, macrolactone, NMR analysis, biosurfactant 
Surfactants of biological origin, i.e., biosurfactants, are increasingly considered as substitutes for synthetic amphiphilic molecules in a wide variety of applications such as emulsifiers in soaps and detergents, oil spill remediation technologies, and in the food and beverage industry. ${ }^{1}$ Microbially-derived biosurfactants are particularly attractive given the ease of large-scale sustainable production using renewable substrates for cultivation. ${ }^{2}$ To satisfy the requirements for various physicochemical properties (e.g. heat and $\mathrm{pH}$ stability and/or activity, foaming, surface tension), an ever-present demand exists for the discovery of novel biosurfactants.

Rhamnolipids, a large family of mono- and dirhamnose-containing glycolipids fused to a dilipidic side chain made of 3-hydroxy fatty acids, are arguably the best-studied biosurfactants and are among the main bacteria-derived biosurfactants produced on a commercial scale. ${ }^{3,4}$ The production of rhamnolipids has been most extensively studied in the Gram-negative bacterium Pseudomonas aeruginosa. ${ }^{5}$ The biosynthesis of rhamnolipids requires the successive function of three enzymes: RhlA, which directs the production of the lipidic precursor 3-(3hydroxyalkanoyloxy)alkanoic acids (HAAs), ${ }^{6,7}$ as well as $\mathrm{RhlB}^{8}$ and $\mathrm{RhlC},{ }^{9}$ two rhamnosyltransferases.

Since $P$. aeruginosa is an opportunistic pathogen classified as a Level 2 biohazard, there are compelling reasons to identify alternative non-pathogenic producers. ${ }^{10}$ Interestingly, genome mining has revealed potential homologues/paralogues of $r h l A / r h l B / r h l C$ in other bacterial species. For instance, several Burkholderia species encode these genes in operons and indeed produce rhamnolipids, although predominantly with a longer fatty acid side chain. ${ }^{11-14}$ Recently, the bacterium Pantoea ananatis was also found to encode rhlA and rhlB homologues. ${ }^{15}$ Similar to P. aeruginosa and Burkholderia, ${ }^{16-18}$ loss of rhlA in P. ananatis BRT175 results in a defect in swarming motility, consistent with a lack of wetting agent 
production. ${ }^{15}$ Indeed, we found that BRT175 produces glycolipidic biosurfactants, which were surprisingly not rhamnolipids. ${ }^{15}$ While previous analyses revealed these glycolipids to contain typical rhamnolipid-like HAA moieties, the sugar portion, although not identified, was shown not to be a rhamnose. ${ }^{15}$ In this Research Note we present the isolation and structural elucidation of the main congener of this new family of biosurfactants, that we have named ananatosides.

P. ananatis was grown with shaking in liquid culture medium for seven days, sedimented, followed by EtOAc extraction of the supernatant. The glycolipid fraction was pre-purified by preparative normal phase TLC (EtOAc/MeOH), followed by semi-preparative reversed phase HPLC $\left(\mathrm{H}_{2} \mathrm{O} / \mathrm{CH}_{3} \mathrm{CN}\right)$ to isolate pure ananatoside $\mathrm{A}(\mathbf{1})$ in the form of a yellow oil. Using tandem mass spectrometry, the structure of glycolipid $\mathbf{1}$ was tentatively identified as a hexose residue linked to two hydroxydecanoic acid chains (Figure 1). ${ }^{15}$

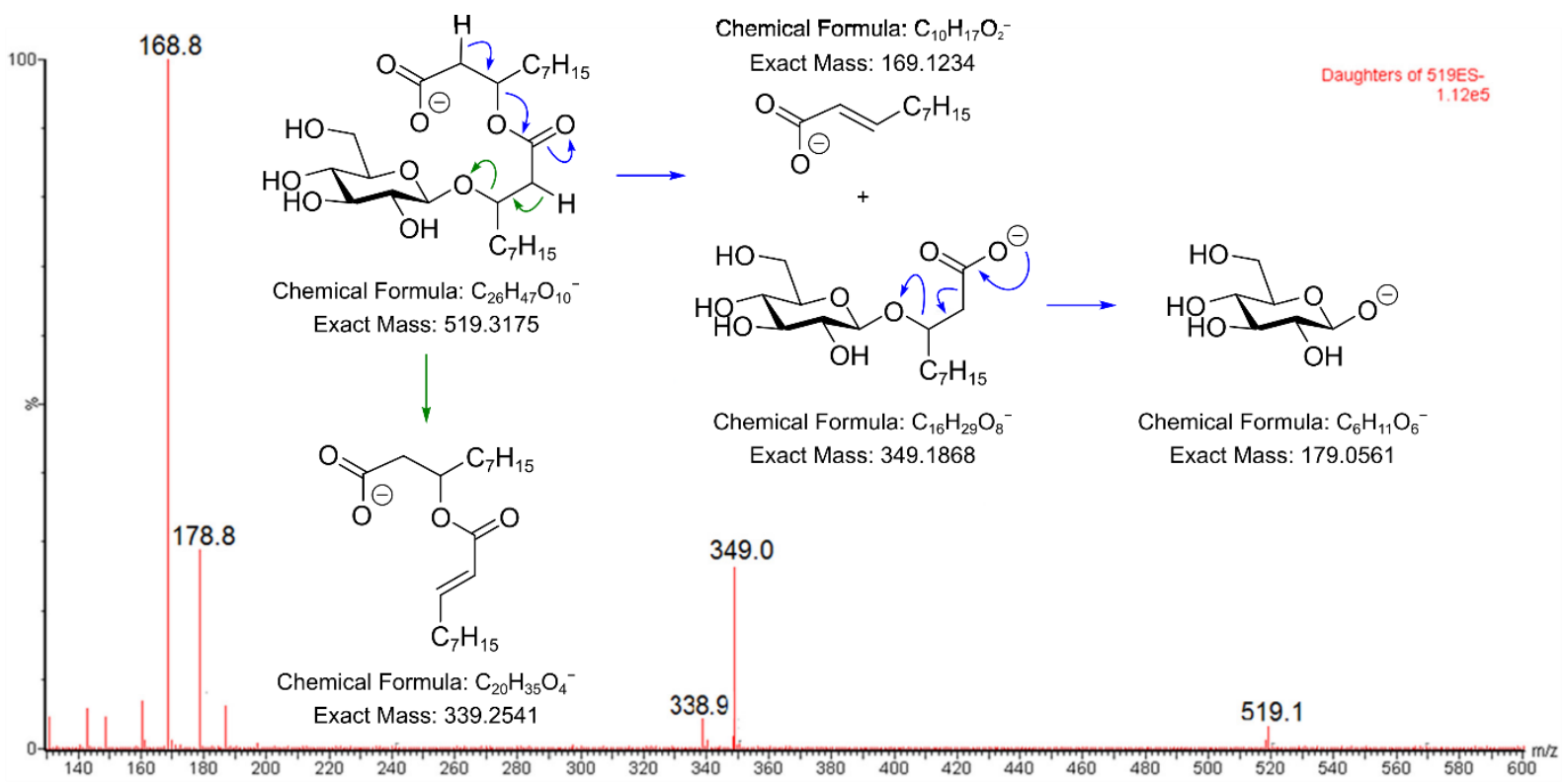

Figure 1. Low resolution tandem mass spectrum (MS/MS) of ananatoside A (1) obtained after fragmentation of the $\mathrm{m} / \mathrm{z} 519$ negative pseudomolecular ion produced in an electrospray ion source (ESI). 
Ananatoside A (1) was then analysed by HR-ESI-TOF-MS in both positive and negative modes, yielding pseudomolecular ion peaks at $m / z 543.3135[\mathrm{M}+\mathrm{Na}]^{+}$and $m / z 519.3171[\mathrm{M}-\mathrm{H}]^{-}$, respectively (see Figures S1-S2), thus confirming previous results. ${ }^{15}$ The nature of the hexose residue was difficult to determine by NMR due to peak overlaps and presence of hydroxylic hydrogens in DMSO- $d_{6}$. Interestingly, after trying different deuterated solvents, we found that the ${ }^{1} \mathrm{H}$ NMR spectra of glycolipid 1 in pyridine- $d_{5}$ showed no peak overlaps for the hexose residue (Figure 2). Careful examination of the ${ }^{1} \mathrm{H}$ and $2 \mathrm{D}{ }^{1} \mathrm{H}-{ }^{1} \mathrm{H}$ COSY NMR spectra of glycolipid 1 in pyridine- $d_{5}$ allowed for the full assignment of all hexose protons (Table 1). A doublet at $\delta_{\mathrm{H}} 5.11\left(\mathrm{~d}, 1 \mathrm{H},{ }^{3} J_{1,2}=8.0 \mathrm{~Hz}, \mathrm{H}-1\right)$ and large coupling constants $(>8.7 \mathrm{~Hz})$ for all other hexose signals were observed on the $J$-resolved NMR spectrum (Figure 3 ) indicating the presence of a $\beta$-glucose residue. The alkyl chains were analysed using COSY and TOCSY NMR spectra. Starting from the oxymethines at $\delta_{\mathrm{H}} 5.89\left(\mathrm{H}-3^{\prime \prime}\right)$ and $4.65\left(\mathrm{H}-3^{\prime}\right)$, spin groups spanning from $\mathrm{H}_{2}-2^{\prime} / \mathrm{H}_{2}-2^{\prime \prime}$ to $\mathrm{H}_{2}-7^{\prime} / \mathrm{H}_{2}-7^{\prime \prime}$ were identified (Figure 4). The carbonyl groups were identified based on HMBC correlations of $\mathrm{H}_{2}-2^{\prime} / \mathrm{H}_{2}-2^{\prime \prime}$ with $\delta_{\mathrm{C}} 172.13\left(\mathrm{C}-1^{\prime}\right)$ and $170.41(\mathrm{C}$ $1 ")$, respectively. The linkage between the glucose and the alkyl chains was determined from HMBC correlations from $\mathrm{H}-1$ to $\mathrm{C}-3^{\prime}$, and from $\mathrm{H}_{2}-6$ to $\mathrm{C}-1$ " (Figure 5). The latter correlation was unexpected given the previously proposed structure of glycolipid 1 (Figure 1). Furthermore, the chemical shifts of the free carboxylic acid $\left(\mathrm{C}-1^{\prime}\right)$ and the ester carbonyl $(\mathrm{C}$ $\left.1^{\prime \prime}\right)$ were almost identical $\left(\left|\Delta \delta_{\mathrm{C}}\right|=1.7\right)$. Also, a thorough examination of the NMR spectra recorded in acetone- $d_{6}$ highlighted a weak correlation between $\mathrm{H}-3^{\prime \prime}$ and both $\mathrm{C}-1^{\prime}$ and C-1" (see Figure S13). This information suggested the presence of a macrodilactone functionality in glycolipid 1 (Figure 4). We thus hypothesized that the acidic conditions used in the ESI source induced the hydrolysis of the lactone functionality to afford a glycolipid having free carboxylic acid and $\mathrm{CH}_{2} \mathrm{OH}$ groups, as shown by the $\mathrm{C}_{26} \mathrm{H}_{48} \mathrm{O}_{10}$ measured molecular structure. Ananatoside A (1) was thus subjected to MALDI-TOF-MS using $\alpha$-cyano-4-hydroxycinnamic acid as the 
matrix. Accordingly, the MALDI analysis produced a pseudomolecular ion peak at $\mathrm{m} / \mathrm{z} 525.2$ $[\mathrm{M}+\mathrm{Na}]^{+}$, supporting a $\mathrm{C}_{26} \mathrm{H}_{46} \mathrm{O}_{9}$ molecular structure featuring a macrodilactone ring (see Figure S3).

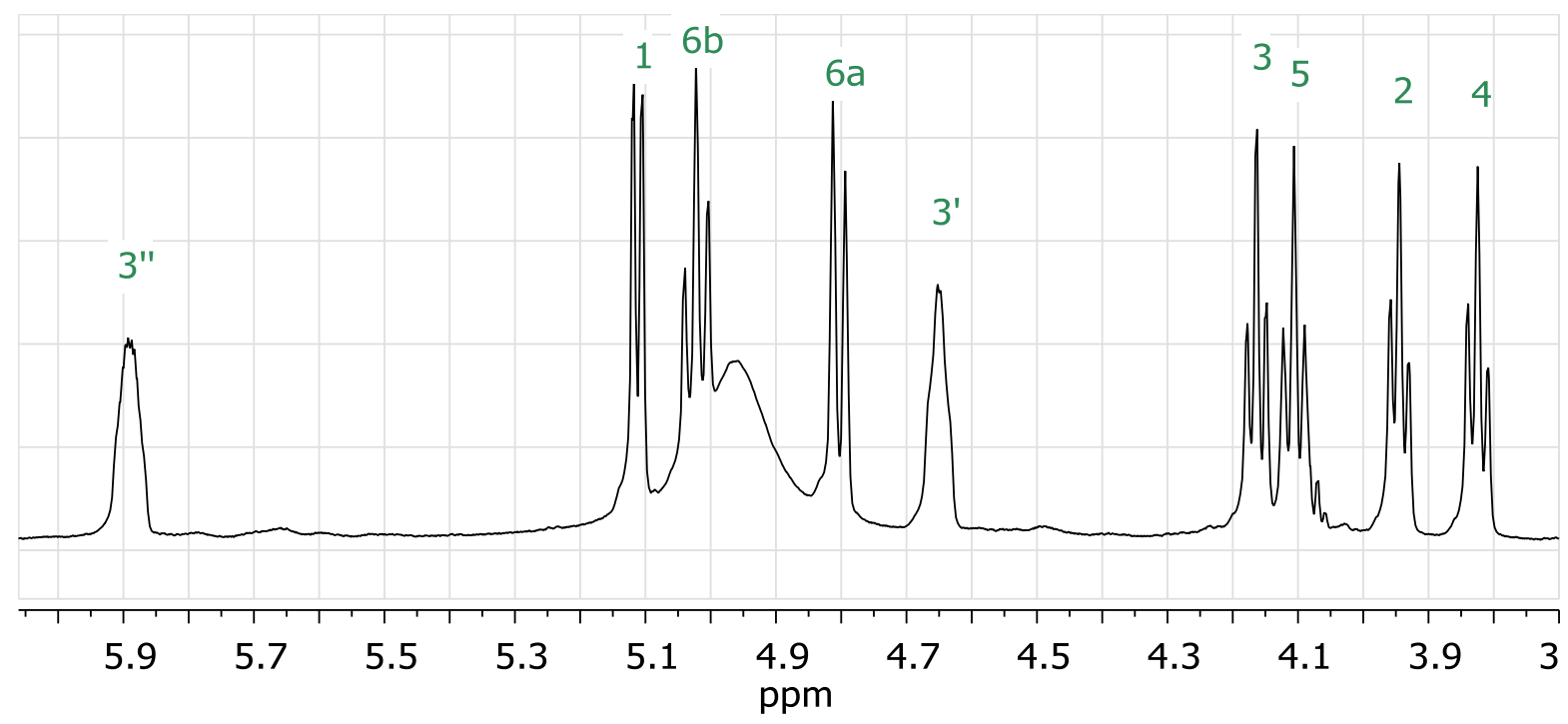

Figure 2. Selected region of the ${ }^{1} \mathrm{H}$ NMR spectrum of ananatoside A (1) in pyridine- $d_{5}$ at $600 \mathrm{MHz}$ (see Fig. 4 for numbering). 
Table 1. ${ }^{1} \mathrm{H}$ and ${ }^{13} \mathrm{C}$ NMR spectroscopic data for ananatoside $\mathrm{A}(\mathbf{1})^{\mathrm{a}}$

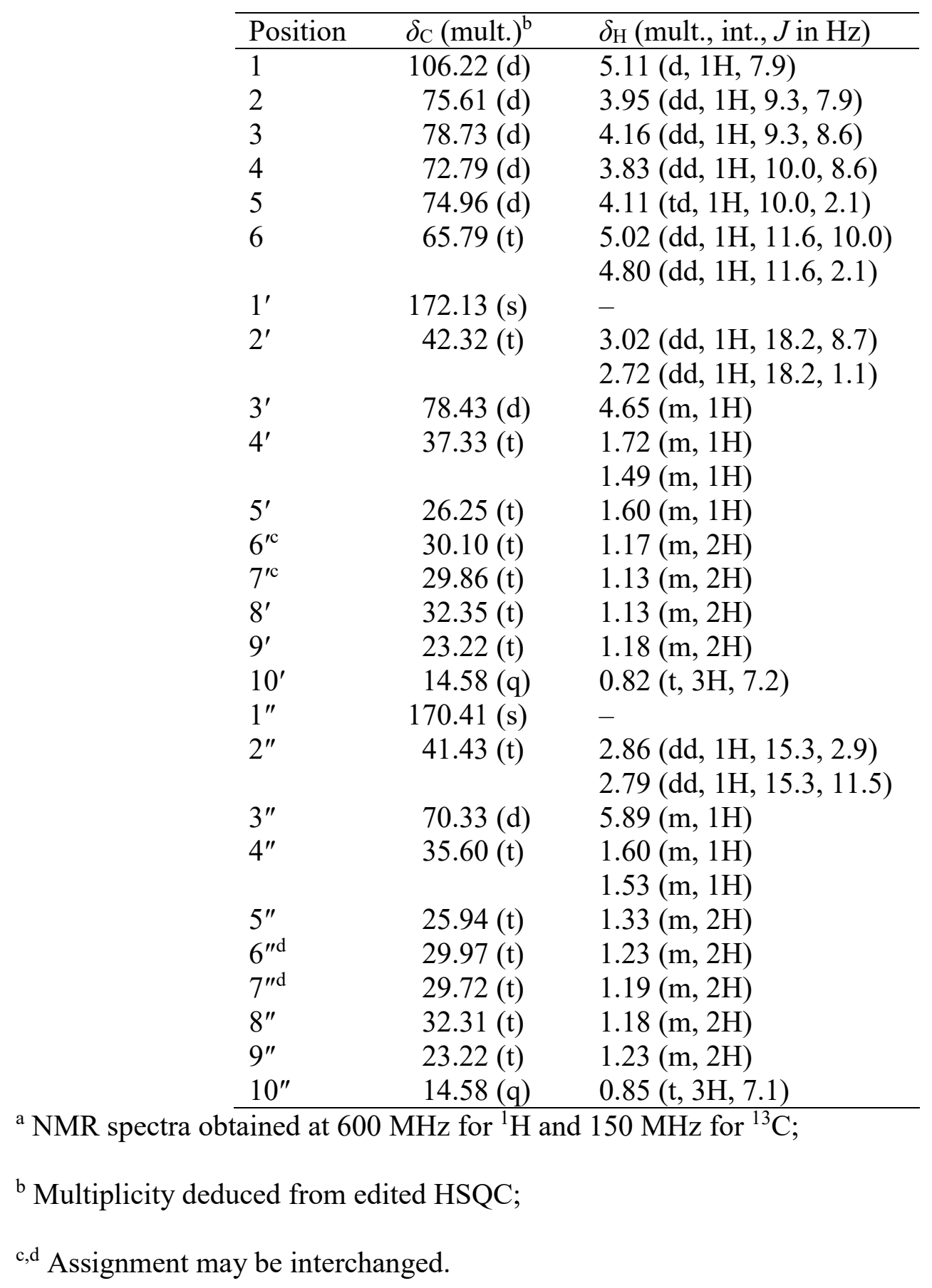




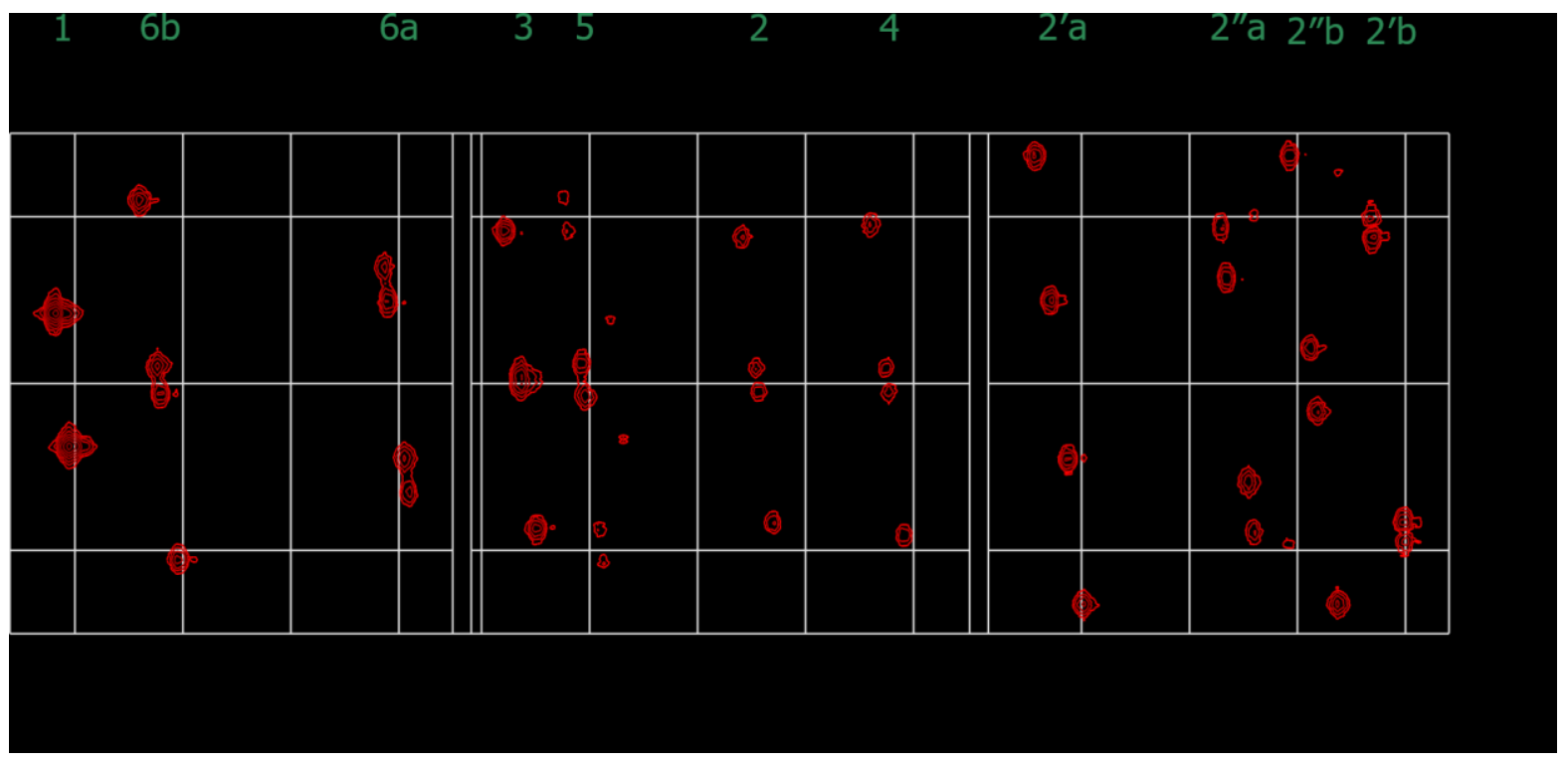

Figure 3. $J$-resolved NMR spectrum of the glucose moiety signals for ananatoside A (1).

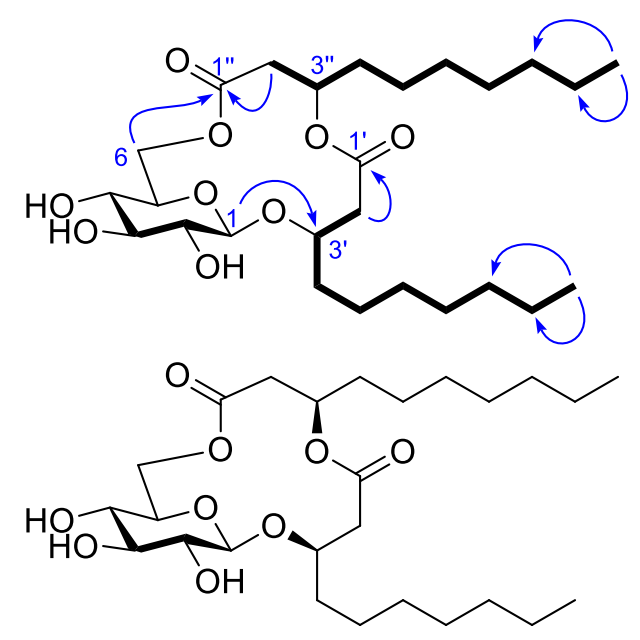

Figure 4. Proposed structure of ananatoside A (1) along with key COSY ( - ) and HMBC ( $\longrightarrow$ ) correlations. 


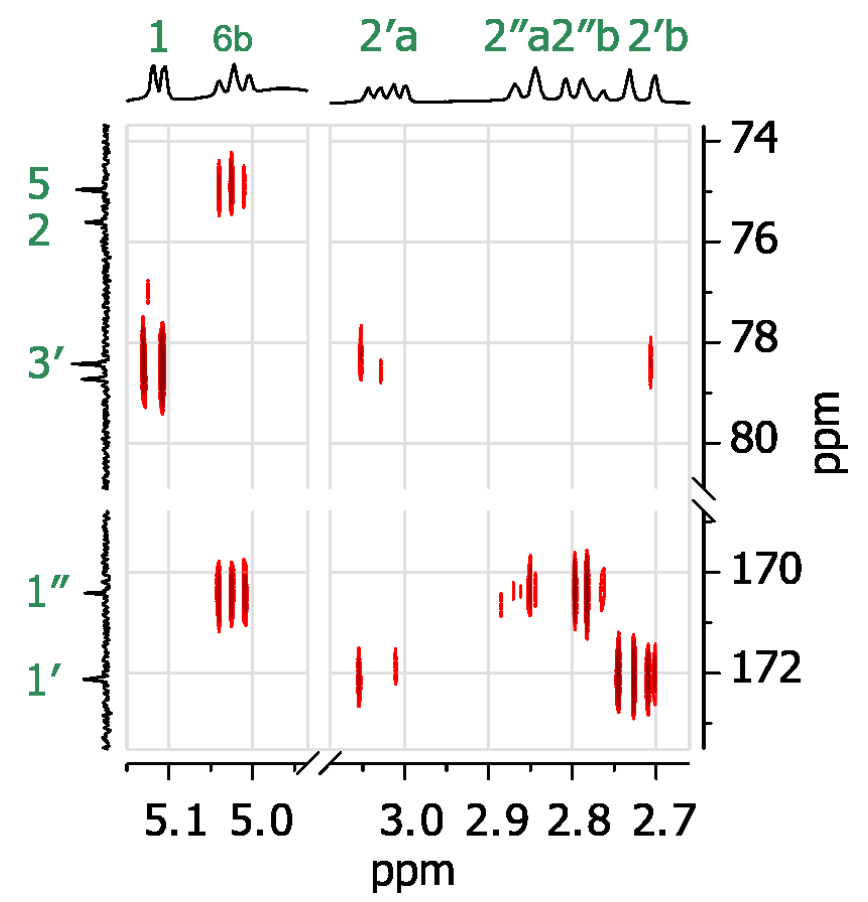

Figure 5. 2D HMBC NMR spectrum of ananatoside A (1) in pyridine- $d_{5}$ showing bonding of the glucose moiety to the fatty acid chains.

In order to get insights into the absolute configuration of both the glucose and fatty acid chains, ananatoside $\mathrm{A}$ (1) was subjected to acid hydrolysis under refluxing $1.0 \mathrm{~N} \mathrm{HCl}$ in $\mathrm{H}_{2} \mathrm{O} / \mathrm{EtOH}$ conditions. ${ }^{19}$ HPLC-MS analysis was used to follow the completion of the reaction. After $1 \mathrm{~h}$, the mixture contained free 3-hydroxydecanoic acid together with its dimer in a $\sim 1: 1$ ratio. Prolonged hydrolysis time (two additional hours) was needed to quantitatively cleave the ester functionality between both fatty acid chains. Following neutralization to $\mathrm{pH} \sim 4$, the lipid moiety was extracted from the aqueous phase with $\mathrm{CHCl}_{3}$. The absolute configuration of 3hydroxydecanoic acid was determined to be $R$ on the basis of its specific rotation by comparison with literature data $\left([\alpha]_{\mathrm{D}}{ }^{20}=-12\left(c 0.2, \mathrm{CHCl}_{3}\right)\right.$, lit. $\left.^{20}[\alpha]_{\mathrm{D}}{ }^{20}=-10.7\left(c 1.0, \mathrm{CHCl}_{3}\right)\right)$. The $R$ configuration of ananatoside A (1) fatty acid chains matched with the one found in naturally occurring bacterial rhamnolipids. ${ }^{21}$ The absolute configuration of the glucose residue was also determined by measuring the optical rotation and was found to be D-(+)-glucose. In addition, GC-MS analysis of the silylated water-soluble sugar fraction in comparison with an authentic 
sample confirmed the identification of glucose (see Fig. S14-S16). On the basis of the above chemical and spectroscopic evidences, the complete structure of ananatoside A (1) was established (Figure 4).

The scalar coupling constants of glycolipid 1 in pyridine- $d_{5}$ were extracted from the $J$-resolved NMR spectrum for almost all protons involved in the macrolactone ring (Table 2). To generate a useful dataset for subsequent studies, we next set out to build a precise in silico molecular model of the structure. A simplified model in which the $\mathrm{C}_{7} \mathrm{H}_{15}$ end groups were replaced by methyls was subjected to a conformational search using Spartan. ${ }^{7}$ As the coupling constants of the glucose protons were well-defined, we constrained their dihedral angles to minimize the conformational space to be explored. This procedure provided only five conformers within a relative energy window of $21 \mathrm{~kJ} \cdot \mathrm{mol}^{-1}$. The geometries were further optimized in Gaussian ${ }^{22}$ using DFT at a mPW1PW91/6-311+G(2d,2p) level of theory. Computation of vibrational frequencies and thermochemical parameters were carried out to ensure that no imaginary frequency was present. The NMR spectroscopic data of the two predominant conformers, accounting for $99 \%$ of the population, were predicted using gauge-independent atomic orbitals (GIAO) method and two-step spin-spin coupling constant calculations. ${ }^{23}$ The results were weight-averaged by the Boltzmann distribution and scaled against the experimental values (Tables 2 and 3). The calculated values were in very close agreement with the experimental values indicating that the model was reliable. The two conformers differed only by the orientation of the $\mathrm{C}-1$ " carbonyl. This difference did not severely impact the coupling constants, helping to explain the sharp signals detected in the ${ }^{1} \mathrm{H}$ NMR spectrum. Also, the proton $\mathrm{H}-3^{\prime}$ was found $2.2 \AA$ apart from the anomeric proton $\mathrm{H}-1$, in both conformers, leading to strong NOESY correlations. 
Table 2. Experimental and calculated coupling constant ( $J$ in $\mathrm{Hz}$ ) for ananatoside A (1).

\begin{tabular}{lrrr}
\hline & Exp. & Calc. $^{\mathrm{a}}$ & \multicolumn{1}{l}{$\Delta$} \\
\hline$J_{1,2}$ & 7.9 & 7.6 & -0.3 \\
$J_{2,3}$ & 9.3 & 9.0 & -0.2 \\
$J_{3,4}$ & 8.6 & 8.4 & -0.2 \\
$J_{4,5}$ & 10.0 & 9.4 & -0.5 \\
$J_{5,6 \mathrm{a}}$ & 2.1 & 2.6 & 0.5 \\
$J_{5,6 \mathrm{~b}}$ & 10.0 & 9.8 & -0.2 \\
$J_{6 \mathrm{a}, 6 \mathrm{~b}}$ & -11.6 & -11.9 & -0.3 \\
$J_{2^{\prime} \mathrm{a}, 2^{\prime} \mathrm{b}}$ & -18.2 & -17.9 & 0.3 \\
$J_{2^{\prime} \mathrm{a}, 3^{\prime}}$ & 8.7 & 8.8 & 0.1 \\
$J_{2^{\prime} \mathrm{b}, 3^{\prime}}$ & 1.1 & 1.2 & 0.1 \\
$J_{2^{\prime \prime} \mathrm{a}, 2^{\prime \prime} \mathrm{b}}$ & -15.3 & -15.7 & -0.4 \\
$J_{2^{\prime \prime} \mathrm{a}, 3^{\prime \prime}}$ & 11.5 & 11.9 & 0.3 \\
$J_{2^{\prime \prime} \mathrm{b}, 3^{\prime \prime}}$ & 2.9 & 3.6 & 0.7 \\
\hline & & rmsd $^{\mathrm{b}}$ & 0.4
\end{tabular}

$\mathrm{MAE}^{\mathrm{b}} \quad 0.7$

${ }^{\text {a }}$ Values calculated at the mPW1PW91/6-311+G(d,p)// mPW1PW91/6-311+G(d,p) level of theory performed with polarizable continuum model (PCM) using pyridine;

${ }^{\mathrm{b}} \mathrm{rmsd}=$ root mean square deviation, $\mathrm{MAE}=$ maximum absolute error. 
Table 3. Experimental and calculated NMR chemical shifts for ananatoside A (1).

\begin{tabular}{|c|c|c|c|c|c|c|}
\hline \multirow[b]{2}{*}{ Position } & \multicolumn{3}{|c|}{$\delta_{\mathrm{C}}$} & \multicolumn{3}{|c|}{$\delta_{\mathrm{H}}$} \\
\hline & Exp. & Calc. $^{\mathrm{a}}$ & $\Delta$ & Exp. & Calc. $^{a}$ & $\Delta$ \\
\hline 1 & 106.2 & 103.4 & -2.8 & 5.11 & 4.75 & -0.36 \\
\hline 2 & 75.6 & 75.3 & -0.3 & 3.95 & 3.56 & -0.38 \\
\hline 3 & 78.7 & 77.4 & -1.3 & 4.16 & 3.99 & -0.18 \\
\hline 4 & 72.8 & 71.6 & -1.2 & 3.83 & 3.80 & -0.03 \\
\hline 5 & 75.0 & 74.2 & -0.8 & 4.11 & 4.03 & -0.07 \\
\hline $6 a$ & 65.8 & 65.7 & -0.1 & 4.80 & 4.55 & -0.26 \\
\hline $6 b$ & - & - & - & 5.02 & 5.26 & 0.24 \\
\hline $1^{\prime}$ & 172.1 & 173.4 & 1.3 & - & - & - \\
\hline $2^{\prime} \mathrm{a}$ & 42.3 & 45.0 & 2.7 & 3.02 & 2.97 & -0.05 \\
\hline $2^{\prime} b$ & - & - & - & 2.72 & 2.74 & 0.03 \\
\hline $3^{\prime}$ & 78.4 & 76.4 & -2.0 & 4.65 & 4.89 & 0.24 \\
\hline $1^{\prime \prime}$ & 170.4 & 172.3 & 1.8 & - & - & - \\
\hline $2^{\prime \prime} \mathrm{a}$ & 41.4 & 45.2 & 3.7 & 2.79 & 2.99 & 0.21 \\
\hline $2^{\prime \prime} b$ & - & - & - & 2.86 & 3.09 & 0.23 \\
\hline \multirow[t]{3}{*}{$3 "$} & 70.3 & 69.3 & -1.0 & 5.89 & 6.28 & 0.39 \\
\hline & & $\mathrm{rmsd}^{\mathrm{b}}$ & 1.9 & & $\mathrm{rmsd}^{\mathrm{b}}$ & 0.24 \\
\hline & & $\mathrm{MAE}^{\mathrm{b}}$ & 3.7 & & $\mathrm{MAE}^{\mathrm{b}}$ & 0.39 \\
\hline
\end{tabular}

${ }^{\text {a }}$ Values calculated at the mPW1PW91/6-311+G(d,p)// mPW1PW91/6-311+G(d,p) level of theory performed with polarizable continuum model (PCM) using pyridine;

${ }^{\mathrm{b}} \mathrm{rmsd}=$ root mean square deviation, $\mathrm{MAE}=$ maximum absolute error. 

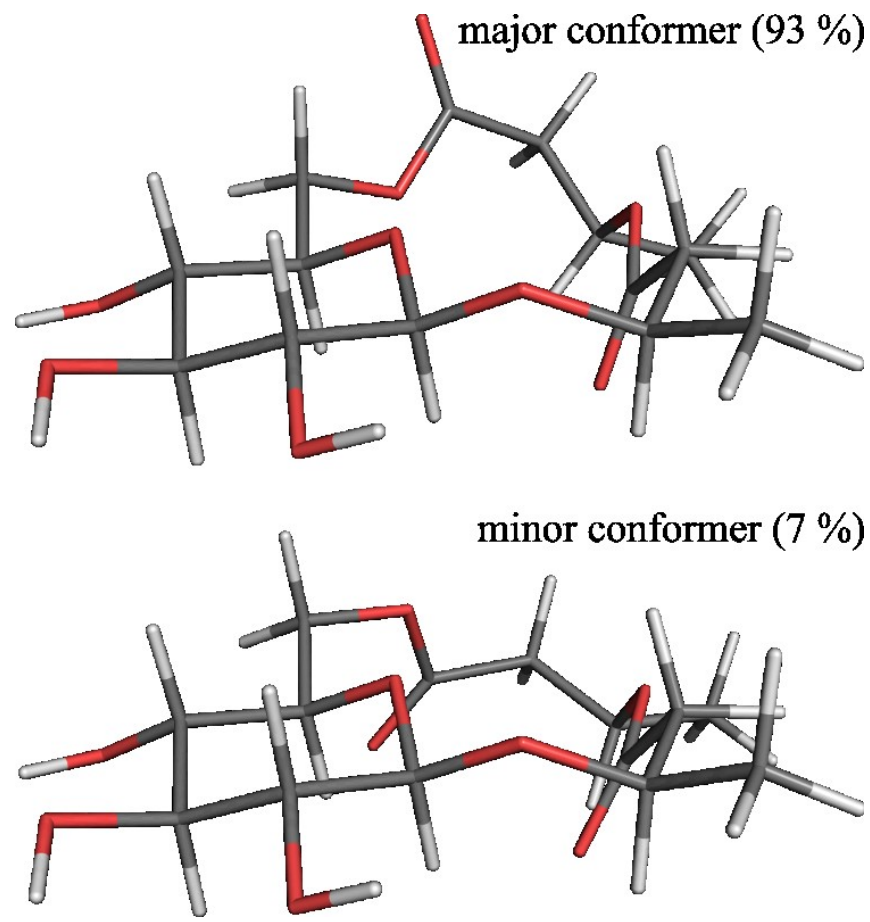

Figure 6. Most stable conformers of ananatoside A (1).

To our knowledge, the isolation of naturally occurring glycolipids featuring a 15 -membered macrodilactone ring is unprecedented. However, glycolipids containing di- and trilactones comprising different macrocycle sizes compared to ananatoside A (1) have been identified from plants and other microorganisms. These include dimers of 4-(glycosyloxy)benzoates, isolated from folk medicinal plants, as well as cycloviracins, fattiviracins, macroviracins, and arthrobacilin A, which have been isolated from the Gram-positive bacteria Kibdelosporangium albatum, Streptomyces microflavus, Streptomyces sp. BA-2836, and Arthrobacter sp. NR2967, respectively. ${ }^{24}$ Some of these glycolipids exhibit potent antiviral activities against herpes simplex virus type I, varicella-zoster virus, influenza virus $A$ and $B$, and human immunodeficiency virus type 1 . Structurally, two or three sugar units are embedded in the macrocycle ring of these compounds in contrast with ananatoside A (1) which contains only one glucose residue. Due to their atypical structures and interesting biological properties, the total synthesis of macrolactone-containing glycolipids have been a persistent challenge for 
organic chemists. ${ }^{24,25}$ Within this framework, it is worth mentioning the synthesis of unnatural 15-membered macrodilactone-containing glycolipids recently described by Si and Peczuh. ${ }^{26}$ In view of its potential biological activity, we believe that ananatoside A (1) could represent an interesting and readily accessible synthetic target for organic chemists.

In summary, we have isolated and structurally identified by chemical and spectroscopic analyses ananatoside A (1), a novel glycolipid from bacterial cultures of $P$. ananatis. This biosurfactant features an unprecedented and unexpected 15-membered macrodilactone ring in which a $\beta$-D-glucose residue is embedded into the macrocycle. During the course of this research project, less abundant glycolipid congeners were detected by LC-MS in the wild-type extract of $P$. ananatis. ${ }^{15}$ Two peaks with $\mathrm{m} / \mathrm{z}$ values of 547.5 and 575.5 point toward the presence of ananatoside congeners featuring two hydroxydodecanoic and hydroxytetradecanoic acid chains, respectively. Similar to ananatoside A (1), we hypothesize that these glycolipid congeners are also found in the form of macrodilactones and that the opened forms $\left[\mathrm{M}+\mathrm{H}_{3} \mathrm{O}\right]^{+}$ were detected under the LC-MS conditions. Work towards the isolation, identification, and evaluation of the biological activities of ananatoside A (1) and its possible congeners is currently in progress in our laboratory.

\section{Experimental}

\subsection{Bacterial culture conditions}

Pre-culture tubes of Pantoea ananatis BRT175 $(3 \mathrm{~mL})$ were grown at $30^{\circ} \mathrm{C}$ in LB medium with shaking (240 rpm) in a TC-7 roller drum (New Brunswick, Canada). Under exponential growth phase, LB medium pre-culture flasks (100 mL each) were seeded with an initial $\mathrm{OD}_{600}$ 
$=0.1$ and cultures were incubated overnight at $30^{\circ} \mathrm{C}$ with shaking $(150 \mathrm{rpm})$. Twelve $2 \mathrm{~L}$ flasks, each containing $500 \mathrm{~mL}$ Mineral Salts Medium (MSM), were inoculated at an initial $\mathrm{OD}_{600}=$ 0.1 and cultures were grown at $30{ }^{\circ} \mathrm{C}$ with shaking $(150 \mathrm{rpm})$. The MSM contained (g/L): 0.9 $\mathrm{Na}_{2} \mathrm{HPO}_{4}, 0.7 \mathrm{KH}_{2} \mathrm{PO}_{4}, 2.0 \mathrm{NaNO}_{3}, 0.1 \mathrm{CaCl}_{2} \cdot 2 \mathrm{H}_{2} \mathrm{O}, 0.4 \mathrm{MgSO}_{4} \cdot 7 \mathrm{H}_{2} \mathrm{O}$, and trace element solution $(2 \mathrm{~mL} / \mathrm{L})$. The composition of trace element solution was $(\mathrm{g} / \mathrm{L}): 2.0 \mathrm{FeSO}_{4} \cdot 7 \mathrm{H}_{2} \mathrm{O}, 1.5$ $\mathrm{MnSO}_{4} \cdot \mathrm{H}_{2} \mathrm{O}$, and $0.6\left(\mathrm{NH}_{4}\right)_{6} \mathrm{Mo}_{7} \mathrm{O}_{24} \cdot 4 \mathrm{H}_{2} \mathrm{O}$. Dextrose $(20 \mathrm{~g} / \mathrm{L})$ was provided as a carbon source. Cultures were grown for seven days.

\subsection{Isolation procedure for ananatoside A (1)}

At the end of the cultivation period, culture supernatant was recovered by centrifugation and concentrated $\mathrm{HCl}$ was added in order to reach a final $\mathrm{pH}=3$. Pooled supernatants (6 L total) were then extracted twice with equal volumes of EtOAc. The organic fractions were then pooled and the solvents were evaporated under reduced pressure to yield a crude extract containing the biosurfactant product. The crude extract $(0.4 \mathrm{~g})$ was resuspended in $\mathrm{EtOH}(2 \mathrm{~mL})$ and this solution was deposited on a preparative normal phase TLC plate. The solvent system was composed of $\mathrm{MeOH} / \mathrm{EtOAc}(1: 4,200 \mathrm{~mL})$ containing $1 \%$ acetic acid. Following migration, glycolipids were visualized using the ceric dip test. ${ }^{27}$ The silica band corresponding to the glycolipids area on the TLC plate was scraped and transferred to a flash chromatography column in order to eluate the glycolipids using $\mathrm{MeOH} / \mathrm{EtOAc}(1: 3,100 \mathrm{~mL})$ as the eluent. Fractions containing the glycolipids, as shown by TLC, were pooled and the solvents were evaporated under reduced pressure to yield a residue $(47 \mathrm{mg})$. The latter $(10 \mathrm{mg})$ was resuspended in $\mathrm{MeOH} / \mathrm{H}_{2} \mathrm{O}(1: 1)$, which was used for semi-preparative HPLC purification. The fractionation was realized using a Gemini-NX $\mathrm{C}_{18}$ reverse-phase column. The injection volume was $20 \mu \mathrm{L}$ and the flow was set to $4 \mathrm{~mL} / \mathrm{min}$. The sequence duration was 27 min using the 
following solvent gradient: $0 \rightarrow 15 \operatorname{min~}_{2} \mathrm{O} / \mathrm{CH}_{3} \mathrm{CN}(50: 50), 15 \rightarrow 18$ min $\mathrm{H}_{2} \mathrm{O} / \mathrm{CH}_{3} \mathrm{CN}$ (10:90), $18 \rightarrow 24 \min 100 \% \mathrm{CH}_{3} \mathrm{CN}, 24 \rightarrow 27 \mathrm{~min}\left(\mathrm{H}_{2} \mathrm{O} / \mathrm{CH}_{3} \mathrm{CN}\right.$ 50:50). The presence of glycolipids (using $\mathrm{m} / \mathrm{z} 519.5$ as the reference) was verified in each fraction following injection by HPLCAPCI-MS (Quattro Premier XE, Waters) in the negative ionization mode. Fractions containing the $m / z 519.5$ glycolipid were pooled and extracted twice with equal volumes of EtOAc. The solvents were evaporated under reduced pressure to give ananatoside A (1, 4.5 mg) as a light yellow oil. $[\alpha]_{\mathrm{D}}{ }^{20}+15\left(c 0.24\right.$, EtOAc); ${ }^{1} \mathrm{H}(600 \mathrm{MHz})$ and ${ }^{13} \mathrm{C}(125 \mathrm{MHz}) \mathrm{NMR}$ data (see Table 1); HRMS (ESI-TOF) $m / z 543.3135\left[\mathrm{M}+\mathrm{Na}+\mathrm{H}_{2} \mathrm{O}\right]^{+}$(calcd for $\left.\mathrm{C}_{26} \mathrm{H}_{48} \mathrm{O}_{10} \mathrm{Na}, 543.3145\right), m / z$ 519.3171 [M - H $\left.+\mathrm{H}_{2} \mathrm{O}\right]^{-}$(calcd for $\mathrm{C}_{26} \mathrm{H}_{47} \mathrm{O}_{10}, 519.3169$ ); MALDI (TOF) $m / z 525.2[\mathrm{M}+$ $\mathrm{Na}]^{+}$(calcd for $\mathrm{C}_{26} \mathrm{H}_{46} \mathrm{O}_{9}, 525.3$ ).

\subsection{NMR analysis}

The 1D and 2D NMR spectra $\left({ }^{1} \mathrm{H},{ }^{13} \mathrm{C},{ }^{1} \mathrm{H}-{ }^{1} \mathrm{H}\right.$ gCOSY, TOCSY, gHSQC, gHMBC, NOESY, $J$-resolved, HSQC band selective) were recorded on a Bruker Avance III HD 600 spectrometer (600 MHz for ${ }^{1} \mathrm{H}$ and $125 \mathrm{MHz}$ for ${ }^{13} \mathrm{C}$ ) equipped with a $5 \mathrm{~mm}$ double resonance broad band probe. Spectra were acquired in DMSO- $d_{6}$, acetone- $d_{6}$ or Py- $d_{5}$, and chemical shifts were reported in ppm $(\delta)$ relative to TMS.

\subsection{HR-ESI-TOF-MS and MALDI-TOF-MS analysis}

Accurate mass analysis (HRMS) was carried out on a TOF 6224 instrument coupled to a 1260 HPLC system both from Agilent technologies. The sample was analysed in loop injection at $0.5 \mathrm{~mL} / \mathrm{min}$. The eluents consisted of $0.1 \%$ formic acid in water (eluent A) and methanol (eluent B) in a constant ratio of 1:1 for a total analysis time of $0.5 \mathrm{~min}$. The dual electrospray 
sources was operated in positive or negative ion mode and mass spectra were acquired from $\mathrm{m} / z 100$ to 3200 . MassHunter was used for data processing and accurate masses were calculated on both the protonated as well as the Na adduct species. The MALDI spectra was obtained on a 4700 MALDI TOF/TOF instrument (Ab Sciex Llc.) in the positive ion reflectron mode. Ananatoside A (1 mg) was co-crystallized with a $10 \mathrm{mg} / \mathrm{mL}$ aqueous solution of $\alpha$-cyano-4hydroxycinnamic acid (CHCA) and air dried prior to MALDI-TOF-MS analysis.

\subsection{Acidic hydrolysis of ananatoside A (1)}

Ananatoside A $(1,2.0 \mathrm{mg})$ was dissolved in EtOH $(400 \mu \mathrm{L})$. Following the addition of a $1 \mathrm{~N}$ $\mathrm{HCl}$ aqueous solution $(600 \mu \mathrm{L})$, the mixture was refluxed for $3 \mathrm{~h}$. Then, EtOH was evaporated under a nitrogen stream. The mixture was transferred into a separatory funnel containing $\mathrm{H}_{2} \mathrm{O}$ (3 mL) and $\mathrm{CHCl}_{3}(2 \mathrm{~mL})$. The aqueous phase was neutralized with a $5 \mathrm{~N} \mathrm{NaOH}$ aqueous solution until $\mathrm{pH} 3-5$. The aqueous phase was extracted three times with $\mathrm{CHCl}_{3}(1 \mathrm{~mL})$, the organic fractions were combined, and the solvent evaporated under a nitrogen stream. Completion of the acidic hydrolysis was confirmed by HPLC-APCI-MS (Quattro Premier XE, Waters) in the negative ionization mode ( $>95 \%$ of monolipid). The hydrolysate was dissolved in $\mathrm{CHCl}_{3}(1 \mathrm{~mL})$ and the optical rotation was measured on a Rudolph Autopol VI polarimeter using a $10 \mathrm{~cm}$ cell at approximately $20^{\circ} \mathrm{C}$. The aqueous phase was directly subjected to optical rotation measurements using the same instrument. Then, the aqueous phase was neutralized with aqueous $\mathrm{Na}_{2} \mathrm{CO}_{3}$ until $\mathrm{pH} \sim 7$ and freeze-dried to give a white amorphous powder. The residue was dissolved in anhydrous pyridine $(1 \mathrm{~mL})$ and treated with chlorotrimethylsilane (13 $\mu \mathrm{L}, \sim 6.0$ equiv $)$ and hexamethyldisilazane $(6.4 \mu \mathrm{L}, \sim 2.0$ equiv $)$ at $0{ }^{\circ} \mathrm{C}$. The reaction was stirred from $0{ }^{\circ} \mathrm{C}$ to room temperature overnight. GC-MS analysis $(30 \mathrm{~m} \times 0.25 \mathrm{~mm}$ ZB-SemiVolatiles column: He, $1 \mathrm{~mL} / \mathrm{min} ; 100^{\circ} \mathrm{C}, 5 \mathrm{~min}, 100-225^{\circ} \mathrm{C}, \Delta 30^{\circ} \mathrm{C} / \mathrm{min}, 225^{\circ} \mathrm{C}, 3 \mathrm{~min}, 225-310{ }^{\circ} \mathrm{C}$, 
$\Delta 40^{\circ} \mathrm{C} / \mathrm{min}, 310^{\circ} \mathrm{C}, 1 \mathrm{~min}$; Programmed Temperature Vaporising splitless injection) gave one peak, $t_{\mathrm{R}} 10.5 \mathrm{~min}$, which coeluted with a standard of $1,2,3,4,6$-penta- $O$-trimethylsilyl- $\beta$-Dglucopyranose synthesized from D-glucose using the previously mentioned conditions (see Fig. S14-S16)

\subsection{Molecular modelling}

Ananatoside A (1) was subjected to quantum-chemical calculation in order to further confirm the proposed structure. First, a simplified 3D model, in which the $\mathrm{C}_{7} \mathrm{H}_{15}$ groups were replaced by methyls, was generated on $\operatorname{Spartan}^{28}$ and a conformer search was done using MMFF94 force field and Monte Carlo algorithm. The dihedral angles for the glucose moiety of the model were constrained. All conformers below a cutoff of $21 \mathrm{~kJ} \mathrm{~mol}^{-1}$ in relative energy were then subjected to a geometrical optimization with the help of Gaussian D09 package. The density of functional theory (DFT) was used at the B3LYP/6-31G* level of theory, and the resulting geometries were refined at the mPW1PW91/6-311+G(2d,2p) level of theory. In both cases, the interaction with the solvent was taken into account with the polarizable continuum model (IEF-PCM, solvent was pyridine). The calculation of the frequencies was carried out in order to derive the thermochemical parameters and to confirm that true minima were obtained (zero imaginary frequency). The values of free energies were extracted to compute the Boltzmann distribution. The shielding tensors were predicted using gauge-independent atomic orbitals (GIAO) at the mPW1PW91/6-311+G(d,p) level of theory, and averaged using their respective Boltzmann weight. The chemical shifts were finally derived by scaling the shielding tensors against the experimental values. The spin-spin coupling constants were predicted using the two-steps algorithm provided in Gaussian ${ }^{23}$ and averaged using the Boltzmann weights. 


\section{Acknowledgements}

This work was supported by Discovery grants from the Natural Sciences and Engineering Research Council of Canada (NSERC) under award numbers RGPIN-2016-04950 (to C. G.) and RGPIN-2015-03931 (to E. D.). C. G. holds a Fonds de recherche du Québec - Santé (FRQS) Research Scholars Junior 2 Career Award. E. D. holds the Canada Research Chair in sociomicrobiology. The chemical modelling was enabled by the use of computing resources provided by WestGrid and Compute Canada. We thank Dr Kenneth Chan, National Research Council Canada, for performing the MALDI analysis, and Dr Alexandre Arnold, Université du Québec à Montréal, for performing the $600 \mathrm{MHz}$ NMR analysis. The authors thank Prof. Salim Timo Islam, INRS-Institut Armand-Frappier, for constructive comments regarding the manuscript.

\section{Supplementary data}

Supplementary data associated with this article can be found, in the online version, at http:/dx.doi.org/10.1016/.

\section{References}

1. Mnif, I.; Ghribi, D. J. Sci. Food Agric. 2016, 96, 4310.

2. Marchant, R.; Banat, I. M. Biotechnol. Lett. 2012, 34, 1597.

3. Abdel-Mawgoud, A. M.; Hausmann, R.; Lépine, F.; Müller, M. M.; Déziel, E. In Biosurfactants: from genes to applications.; 1st ed.; Soberón-Chávez, G., Ed.; Springer: 2011; Vol. 20, p 13. 
4. Müller, M. M.; Kügler, J. H.; Henkel, M.; Gerlitzki, M.; Hörmann, B.; Pohnlein, M.; Syldatk, C.; Hausmann, R. J. Biotechnol. 2012, 162, 366.

5. Soberon-Chavez, G.; Lepine, F.; Deziel, E. Appl. Microbiol. Biotechnol. 2005, 68, 718.

6. Déziel, E.; Lépine, F.; Milot, S.; Villemur, R. Microbiology 2003, 149, 2005.

7. Zhu, K.; Rock, C. O. J. Bacteriol. 2008, 190, 3147.

8. Ochsner, U. A.; Fiechter, A.; Reiser, J. J. Biol. Chem. 1994, 269, 19787.

9. Rahim, R.; Ochsner, U. A.; Olvera, C.; Graninger, M.; Messner, P.; Lam, J. S.; SoberonChávez, G. Mol. Microbiol. 2001, 40, 708.

10. Chong, H.; Li, Q. Microb. Cell Fact. 2017, 16, 137.

11. Andrä, J.; Rademann, J.; Howe, J.; Koch, M. H.; Heine, H.; Zähringer, U.; Brandenburg, K. Biol. Chem. 2006, 387, 301.

12. Costa, S. G.; Déziel, E.; Lépine, F. Lett. Appl. Microbiol. 2011, 53, 620.

13. Dubeau, D.; Deziel, E.; Woods, D. E.; Lepine, F. BMC Microbiol. 2009, 9, 263.

14. Häussler, S.; Nimtz, M.; Domke, T.; Wray, V.; Steinmetz, I. Infect. Immun. 1998, 66, 1588.

15. Smith, D. D. N.; Nickzad, A.; Déziel, E.; Stavrinides, J. mSphere 2016, 1, e00075.

16. Dubeau, D.; Déziel, E.; Woods, D. E.; Lépine, F. BMC Microbiol. 2009, 9, 263.

17. Köhler, T.; Curty, L. K.; Barja, F.; Van Delden, C.; Pechère, J.-C. J. Bacteriol. 2000, 182, 5990.

18. Nickzad, A.; Lépine, F.; Déziel, E. PLoS ONE 2015, 10, e0128509.

19. Leon, I.; Enriquez, R. G.; Nieto, D. A.; Alonso, D.; Reynolds, W. F.; Aranda, E.; Villa, J. J. Nat. Prod. 2005, 68, 1141.

20. Nakahata, M.; Imaida, M.; Ozaki, H.; Harada, T.; Tai, A. Bull. Chem. Soc. Jap. 1982, 55, 2186.

21. Abdel-Mawgoud, A.; Lépine, F.; Déziel, E. Appl. Microbiol. Biotechnol. 2010, 86, 1323. 
22. Frisch, M. J.; Trucks, G. W.; Schlegel, H. B.; Scuseria, G. E.; Robb, M. A.; Cheeseman, J. R.; Scalmani, G.; Barone, V.; Petersson, G. A.; Nakatsuji, H.; Li, X.; Caricato, M.; Marenich, A. V.; Bloino, J.; Janesko, B. G.; Gomperts, R.; Mennucci, B.; Hratchian, H. P.; Ortiz, J. V.; Izmaylov, A. F.; Sonnenberg, J. L.; Williams; Ding, F.; Lipparini, F.; Egidi, F.; Goings, J.; Peng, B.; Petrone, A.; Henderson, T.; Ranasinghe, D.; Zakrzewski, V. G.; Gao, J.; Rega, N.; Zheng, G.; Liang, W.; Hada, M.; Ehara, M.; Toyota, K.; Fukuda, R.; Hasegawa, J.; Ishida, M.; Nakajima, T.; Honda, Y.; Kitao, O.; Nakai, H.; Vreven, T.; Throssell, K.; Montgomery Jr., J. A.; Peralta, J. E.; Ogliaro, F.; Bearpark, M. J.; Heyd, J. J.; Brothers, E. N.; Kudin, K. N.; Staroverov, V. N.; Keith, T. A.; Kobayashi, R.; Normand, J.; Raghavachari, K.; Rendell, A. P.; Burant, J. C.; Iyengar, S. S.; Tomasi, J.; Cossi, M.; Millam, J. M.; Klene, M.; Adamo, C.; Cammi, R.; Ochterski, J. W.; Martin, R. L.; Morokuma, K.; Farkas, O.; Foresman, J. B.; Fox, D. J. Wallingford, CT, 2016.

23. Deng, W.; Cheeseman, J. R.; Frisch, M. J. J. Chem. Theory Comput. 2006, 2, 1028.

24. Xie, J.; Bogliotti, N. Chem. Rev. 2014, 114, 7678.

25. Fürstner, A. Eur. J. Org. Chem. 2004, 943.

26. Si, D.; Peczuh, M. W. Carbohydr. Res. 2016, 434, 113.

27. Mechaly, A.; Belakhov, V.; Shoham, Y.; Baasov, T. Carbohydr. Res. 1997, 304, 111. 28. Wavefunction, Inc.: Irvine, CA. 